\title{
Poder E INFLUENCIA EN CONTEXTOS DE PROHIBICIÓN DE REELECCIÓN consecutiva: el caso de la Cámara de Diputados de México
}

\author{
Power and Influence Under the Prohibition of Consecutive Reelection: \\ The Case of the Chamber of Deputies of Mexico
}

\section{CARLOS VÁZQUEZ FERREL}

Instituto Tecnológico y de Estudios Superiores de Monterrey, México

\author{
ALEJANDRO DÍAZ DOMÍNGUEZ \\ Instituto Tecnológico y de Estudios Superiores de Monterrey, México
}

\begin{abstract}
RESUMEN
Los liderazgos partidistas buscan aquellos congresistas con competencias técnicas y trayectorias que les permitan conducir el proceso legislativo y con el ascendente político para colaborar en la coordinación del grupo parlamentario y la interlocución con otras fuerzas partidistas. Se analizan tres legislaturas de la Cámara de Diputados en México entre 2009 y 2016, empleando iniciativas presentadas y aprobadas, presidencias de comisión e integración de comisiones relevantes como variables dependientes, mientras que como explicativas las de género, método de elección y trayectoria educativa, legislativas, partidistas y experiencia en la administración pública. Esto con el objetivo de conocer algunos de los determinantes del poder institucional en un Congreso sui generis, dado que su sistema electoral mixto coexiste con la prohibición de la reelección consecutiva. Los hallazgos muestran que, en estos contextos, los liderazgos partidistas en el Poder Legislativo parecen inclinarse a escoger a hombres y no a mujeres parlamentarias para posiciones de poder; quienes son mayormente electos por el principio de representación proporcional y no a los que compitieron por mayoría relativa; así como a quienes cuentan con experiencia legislativa y partidista previa, donde las trayectorias políticas desde lo local hasta lo nacional también pueden recibir mayores oportunidades.
\end{abstract}

Palabras clave: Congreso, México, no reelección consecutiva, trayectoria política, género, método de elección

\begin{abstract}
Party leaders seek candidates with the technical competence and career trajectories necessary to allow them to negotiate the legislative process, as well as to collaborate with the party leadership in relation to the coordination of both inter-and intra-party affairs. Using data from three legislative cycles of the Mexican Chamber of Deputies (2009 to 2016), we seek to explain the parliamentary actions of legislators in relation to characteristics such as their gender, mode of election, prior experience, and educational, legislative and partisan backgrounds. The objective is to identify some of the determinants of institutional power in a sui generis congress conditioned by the use of a mixed electoral system and a prohibition on consecutive re-election. The findings show that partisan leadership opportunities in the legislative branch tend to favor male legislators, those elected from party lists (as opposed to those elected by local majorities), those with previous legislative and partisan experience, and those whose political trajectories have seen them advance from the local to the national level.
\end{abstract}

Keywords: Congress, Mexico, term limits, political careers, gender, electoral rules 


\section{INTRODUCCIÓN}

La "conexión electoral" propuesta por Mayhew (1974) es una de las explicaciones más difundidas para comprender el comportamiento de los legisladores en los Estados Unidos de América (EE. UU.). Su comportamiento — siguiendo a este autor- está guiado por un solo objetivo: lograr la reelección. Para ello, los legisladores promueven políticas específicas, buscan asentarse en instancias del Congreso, como comisiones relevantes donde pasan gran tiempo de su vida legislativa, las cuales consideran estratégicas para la promoción de sus intereses. Del mismo modo, la organización y reglas están diseñadas para visibilizar el actuar del legislador; para que sus votantes, en dicho caso, le recompensen con la reelección y así los partidos obtengan ventajas de la experiencia acumulada de sus legisladores, ubicando a quienes cuentan con mayor trayectoria - a través del seniority system - en instancias de autoridad e influencia en la toma de decisiones.

Sin embargo, la realidad legislativa internacional es distinta a la de EE. UU. En América Latina, por ejemplo, las altas tasas de reelección — similares a las estadounidenses - se encuentran lejos de aparecer en algún Congreso de la región (Morgenstern 2006). Además, esta región convive con una característica institucional distintiva: los partidos políticos suelen jugar un papel crucial para organizar la actividad legislativa. El peso de estas orgánicas partidarias tiende a reducir la autonomía de las comisiones. Aunque existen algunas comisiones que, por su composición - la cual incluye liderazgos con trayectoria y conexiones en los ámbitos local y nacional-y por la importancia de las políticas que analizan y los recursos que redistribuyen, resultan instancias deseadas por quienes buscan escalar en sus carreras por el poder (Alemán 2008). En esta realidad de alta rotación legislativa e intermediación de los partidos políticos, la "conexión electoral" propuesta por Mayhew y las reglas de ubicación surgidas del seniority system tienden a erosionarse.

¿Qué criterios intervienen en la distribución de posiciones estratégicas y de influencia en contextos sin un claro seniority system? ¿Cuáles son algunas de las consecuencias de la puesta en marcha de estos criterios en la dinámica legislativa? Las características del sistema electoral mexicano hacen de su estudio un caso atractivo para abordar estas interrogantes. Al igual que otros países de América Latina, México cuenta con un sistema multipartidista basado en entidades centralizadas pero, a diferencia de la gran mayoría de países, el sistema de multipartidista mexicano convive con un régimen electoral mixto y la prohibición de la reelección consecutiva de los puestos de elección, por lo que cada trienio se renueva la totalidad del Congreso ${ }^{1}$. En este contexto, los determinantes de la distribución de posiciones estratégicas incluyen factores

Esta prohibición fue levantada con la reforma constitucional de 2014, que permite a los legisladores nacionales, a partir de 2018, buscar la reelección consecutiva hasta por cuatro periodos más. La legislatura que inició en 2015 fue la última donde la prohibición de reelección consecutiva se mantuvo vigente. 
que van más allá de las reglas de operación interna del Congreso, las cuales repercuten en la distribución de influencias y poder en el funcionamiento legislativo.

Además, el sistema electoral mixto en México, como en los casos de Alemania, Escocia, Gales y Nueva Zelanda, entre otros, permite comparar patrones de comportamiento entre integrantes del Poder Legislativo que llegan a un escaño por mayoría relativa o por representación proporcional, sin necesidad de contrastar países (Ugues Jr et al. 2012: 98). Esto es así porque en la misma Cámara coexisten ambos tipos de representación, la proporcional y la mayoritaria, lo que también posibilita realizar una comparación controlada. Adicionalmente, el principio de prohibición en la reelección consecutiva, que perduró en México entre los años 1934 y 2018, pudo limitar los efectos de la conexión electoral entre representantes y ciudadanía e interrumpir la continuidad en la curva de aprendizaje (Ugues Jr et al. 2012: 108).

Las investigaciones sobre la distribución de espacios de liderazgo e influencia en contextos legislativos de prohibición de reelección consecutiva son escasos. Sin embargo, existen notables excepciones para el caso de México (Aparicio y Langston 2009; Kerevel 2010; Ugues Jr et al. 2012; Kerevel y Atkeson 2013). A diferencia de esos estudios previos, este trabajo aporta nueva evidencia que enfatiza en trayectorias legislativas, partidistas y en la administración pública, tanto para el ámbito nacional como para los locales, así como la formación educativa como factores que inciden en la distribución de posiciones de liderazgo en la Cámara de Diputados. El periodo de estudio - que abarca las legislaturas LXI, LXII y LXIII, esto es, de 2009 a 2016 y suma un total de 1520 legisladores - incluye la ampliación de la cuota de género (ahora paridad), la cual originó que la presencia de la mujer en el Congreso mexicano alcanzara niveles sin precedentes en la historia legislativa (42 \%) del país.

Con esta base empírica, se argumenta que los liderazgos partidistas buscan a aquellos parlamentarios con competencias técnicas y amplia trayectoria que les permitan conducir el proceso legislativo y con el ascendente político, para colaborar con las élites de estos conglomerados en las tareas de coordinación del propio grupo parlamentario y la interlocución con otras fuerzas partidistas. Son el exclusivo círculo de legisladores que reúne estas características de liderazgo, es ubicado en posiciones estratégicas en el Congreso, donde se encuentran en condiciones privilegiadas para intercambiar apoyos y promover exitosamente sus intereses. Si bien la prohibición de la reelección consecutiva ha jugado un papel central en los orígenes y desarrollo del reparto del poder institucional en la Cámara de Diputados mexicana, también debe resaltarse que se ve potenciada por la puesta en juego de otros factores. Se trata, en particular, de reglas internas del propio Congreso, las cuales otorgan poder a los líderes de las fracciones parlamentarias sobre recursos materiales, humanos y económicos (Ugues Jr et al. 2012: 101); reglas electorales que, al definir listas bloqueadas y cerradas, permiten el control partidista sobre la representación proporcional; y de reglas al interior de cada organización partidista, las cuales permiten tanto el 
ejercicio centralizado de la dirigencia, como el establecimiento de compromisos interpersonales que trascienden los lazos institucionales.

\section{MARCO TEÓRICO}

El objetivo de este artículo es analizar los determinantes de la distribución de puestos de liderazgo y la capacidad de promover intereses en el Congreso exitosamente, todo ello en un contexto de prohibición de reelección consecutiva. La organización del Poder Legislativo genera asimetrías en los recursos institucionales a disposición de sus integrantes. Para evitar que el congestionamiento obstruya el desahogo del trabajo legislativo, una parte de la literatura ha argumentado que, en su evolución, los parlamentos se dotaron de instancias de liderazgo con "poder de agenda", las cuales regulan el acceso, por ejemplo, al pleno, calendarizan votaciones o evitan que una determinada iniciativa recorra el trámite legislativo, especialmente cuando los integrantes de la fracción del Congreso no muestran acuerdos sobre el tema (Cox 2006).

En la base de la también denominada "teoría del cartel" reposan la importancia de la reelección, una política pública acorde y la posibilidad de mantener una condición parlamentaria mayoritaria. Debe resaltarse que, en el contexto mexicano, entre 1934 y 2018, la primera de las bases de esta teoría debe matizarse con los términos "no consecutiva". Asimismo, también se desarrollan áreas de especialización - las comisiones-, que son subconjuntos del Congreso organizados en función de temáticas específicas, con recursos y poderes de agenda propios para controlar la producción legislativa.

La relación entre las características de cada integrante de la legislatura y la comisión a la que pertenece es un tema abordado principalmente en el Congreso estadounidense. Desde Masters (1961) se reconoció la pertenencia a una determinada comisión como un factor crucial para explicar la alta longevidad de los legisladores en dichos espacios. Masters (1961) también explicitó las diferencias entre las comisiones con mayor influencia sobre la agenda del Congreso de aquellas con incidencia en políticas particulares, además de mostrar cómo el seniority system influía en cuáles integrantes de la legislatura pertenecerían a cierto tipo de comisiones o incluso las presidieran.

Sin embargo, Squire (1988) mostró la diversidad en cuanto a maneras de distribuir puestos de poder, sobre todo en los congresos estatales de los EE. UU., específicamente los de Nueva York, California y Connecticut. Este autor puso de relieve que un débil seniority system y una mayor rotación puede derivar en la concentración de influencia en grupos reducidos y convertir al resto de los integrantes en el medio que dote de la cohesión necesaria para la funcionalidad del Congreso. Recientemente, la introducción de límites legales a la reelección y el consecuente incremento en la rotación legislativa en el ámbito estatal estadounidense ha generado una "corriente fructífera" de estudios (MacKenzie y Kousser 2014). 
En América Latina, región con alta rotación parlamentaria, diversos estudios señalan la existencia de reducidos grupos que, frente a la gran mayoría de sus colegas, cuentan con habilidades para conducir el proceso legislativo (Martínez 2006). Por ejemplo, Crisp et al. (2009) muestran que, en Argentina, los integrantes experimentados alcanzan más del doble de probabilidades que sus pares inexpertos para ubicarse en comisiones con incidencia en el proceso de generación de leyes. Éstos, a su vez, poseen apoyos políticos locales, los cuales les promueven en instancias estratégicas del Congreso para que defiendan a los propios intereses regionales.

En línea con estos últimos, diferentes diseños institucionales introducen diversos incentivos al comportamiento. Múltiples estudios señalan que los legisladores tienden a actuar de manera distinta en función del método por el cual fueron electos (Shugart y Carey 1992; André et al. 2004). Los legisladores electos por el principio de mayoría relativa sostienen un comportamiento proclive a visibilizar su imagen, posicionándose en espacios de liderazgo y en promocionar intereses relevantes en su localidad para reclamar crédito por ello (Lundberg 2007). En contraste, legisladores electos por el principio de representación proporcional, en listas cerradas y bloqueadas, tienden a promover intereses vinculados al partido que los seleccionó y de ámbitos geográficos amplios, como lo sería el nacional (Crisp et al. 2004).

El diseño electoral mexicano contempla legisladores escogidos por ambos métodos de elección. Sin embargo, dado que este sistema de elección mixta interactúa con la prohibición de la reelección consecutiva, los supuestos de estas teorías no necesariamente se observarían en la realidad. Otra característica institucional que incide sobre el comportamiento de los legisladores es la organización de los partidos mexicanos, que concentra la toma de decisiones en los liderazgos partidistas (Nacif 2002). No obstante, la aplicación de tales decisiones es realizada en un complejo entorno legislativo derivado de la ausencia de mayorías partidistas en el Congreso. Ambos aspectos son abordados a continuación.

\section{INSTITUCIONES POLÍTICAS MEXICANAS: CONGRESO SIN MAYORÍAS, MODELO CENTRALIZADO DE PARTIDOS Y “CONEXIÓN" ELECTORAL}

La prohibición de la reelección en México convive con dos características institucionales clave: la ausencia —desde 1997 a la fecha-de mayoría absoluta por un solo partido (50 \% más uno) y partidos políticos que mantienen un modelo de organización centralizado. La ausencia de mayorías en el Congreso ha derivado en que la aprobación de las iniciativas dependa de la forja de coaliciones. Algunos de los efectos son: el incremento en la aprobación de leyes - cuando dichas coaliciones existen-, la relevancia del Congreso mexicano en la producción parlamentaria, la intensificación de negociaciones e intercambios 
entre partidos políticos y la carencia de atribuciones legislativas suficientes del Ejecutivo federal para presionar al Congreso (Béjar 2014; Vázquez 2017).

El diseño institucional, especialmente el sistema electoral y la prohibición de la reelección consecutiva, ha consolidado un modelo de partido centralizado en México. La nominación de candidatos que contienden recae principalmente en los liderazgos partidistas, aunque esta selección no está libre de restricciones en las diferentes elecciones. Los gobernadores y otros importantes agentes políticos locales también influyen en el proceso de nominación (Bruhn y Wuhs 2016). Por su parte, la prohibición de la reelección inmediata evita que los votantes puedan recompensar con su voto a quienes buscan la incumbencia. Por ello, su actuación en el Congreso está pautada por la lealtad a quien les nominó y, principalmente, por la ambición que los lleva a cultivar nuevas adhesiones hacia quienes ofrezcan oportunidades de escalar su carrera política. En síntesis, los liderazgos partidistas nacionales y los factores locales controlan gran parte de los puestos políticos, poniendo en sus manos el futuro de legisladores aspirantes a nuevos cargos.

Los gobernadores suelen delegar gran parte de su relación con la Cámara de Diputados en las dirigencias partidistas nacionales, como ocurre en otros países organizados federalmente, como Argentina (Jones y Hwang 2005; Kikuchi y Lodola 2014) y Brasil (Cheibub et al. 2009), aunque durante coyunturas específicas - como negociaciones presupuestales - los gobernadores mexicanos intentan influir directamente en este proceso, pues afecta los ingresos de sus Estados (Langston 2013).

Determinar el peso real de los factores subnacionales sobre el comportamiento parlamentario ha impulsado diversos estudios centrados en el caso mexicano (Ishiyama y Langston 2006, Langston 2010; Rosas y Langston 2011). Sin embargo, éstos no han identificado claramente si se producen diferencias evidentes en la arena legislativa entre lo mandatado por la dirigencia nacional de los partidos y estos factores subnacionales, pues han centrado su atención respecto de si los factores locales guardan o no un peso importante en la actividad del Congreso. Por ejemplo, si quien encabeza el gobierno estatal pertenece a un partido político distinto del Presidente, es más probable que la legislatura local envíe iniciativas de ley al Congreso Federal (Ugues Jr et al. 2017). Ello sugiere que los parlamentos locales también pueden jugar un papel importante para combatir el centralismo según la realidad política local.

Las dirigencias nacionales de los partidos delegan en los coordinadores de sus grupos parlamentarios la función de defender y articular los intereses colectivos de la agrupación en el Congreso. Los coordinadores, por su parte, delegan en sus agentes en comisiones - principalmente, los presidentes de éstas- la función de analizar las legislaciones propuestas, apoyarlas para que superen la etapa de revisión o evitar que lleguen a votarse en el pleno. Sin embargo, dado que el futuro de diputados y senadores depende de las dirigencias partidistas nacionales y de factores subnacionales, la autonomía de las comisiones se ve 
debilitada. La alta cohesión en las votaciones nominales que se aprecia en los grupos parlamentarios es otro reflejo del proceso de delegación de los liderazgos partidistas para organizar la actividad legislativa (Nacif 2002).

Esta alta cohesión partidista convive también con la revitalización del Congreso mexicano. Inaugurada la etapa del Congreso sin mayorías en 1997, se incrementó sustancialmente la promoción y aprobación de leyes, lo que dinamizó también el trabajo en comisiones. En efecto, Vázquez (2017) detectó que, de las iniciativas de ley enviadas por el Poder Ejecutivo a la Cámara de Diputados entre 1997 y 2012 y aquellas que fueron efectivamente aprobadas, la mitad recibió modificaciones en comisiones, algunas de forma cuantiosa ${ }^{2}$.

Este desdoble de la actividad legislativa se produce también en un contexto de prohibición a la reelección consecutiva. Si los estudios ya citados identifican que la alta rotación de representantes tiende a concentrar el poder e influencias en grupos reducidos de parlamentarios, entonces sería lógico esperar que los esmerados procesos de delegación de los liderazgos partidistas hacia sus agentes en el Congreso conlleven el empoderamiento de cierto tipo de congresistas. A saber, quienes reúnan las competencias técnicas para aplicar las decisiones de un determinado grupo en los procesos legislativos y el ascendente político para coadyuvar en las labores de coordinación e interlocución con otras fuerzas.

\section{ALGUNOS ARGUMENTOS E HIPÓTESIS}

Existen múltiples maneras de enfocar el poder e influencia en los órganos legislativos. Un sello distintivo de todo Parlamento democrático es su carácter de institución legitimada para la aprobación de las políticas (Loewenberg et al. 1985). Dentro de las diversas aproximaciones teóricas para comprender su funcionamiento, una línea de estudios enfatiza en el rol desempeñado por los partidos para coordinar la actividad legislativa. Cox y McCubbins (1993), basados en el Congreso de los EE. UU., argumentan que para superar los desafíos de la acción colectiva, los liderazgos de los grupos partidistas fungen como ejes facilitadores de la cooperación y de construcción de coaliciones.

Por su parte Amorim et al. (2003), centrándose en el caso brasileño, identificaron una forma de funcionamiento del Congreso basado en la forja de una coalición multipartidista mayoritaria estable, asemejada a un "cartel legislativo", el cual coloca a sus agentes en instancias de autoridad. Este mecanismo de coordinación y de dirección permite a la coalición con más representantes electos manejar la agenda de discusión, impulsar exitosamente sus políticas y bloquear la tramitación de asuntos contrarios a sus intereses.

2 El Poder Ejecutivo envió ciento once iniciativas y recibió 1647 enmiendas. En promedio, las iniciativas tuvieron 17,3 modificaciones a lo largo de su respectiva tramitación (Vázquez 2017). 
En el caso mexicano se han identificado intensos intercambios y negociaciones entre las principales fuerzas políticas representadas en la Cámara de Diputados, acompasadas por etapas de distanciamiento y confrontación con el partido en el gobierno, desencadenadas por el ciclo electoral (Fernández-Albertos y Lapuente 2010). Diversos trabajos señalan que la dinámica del surgimiento de una coalición mayoritaria de gobierno y un bloque opositor se mueve en dos dimensiones. La primera es el continuum izquierda-derecha, que ubicaría al Partido Revolucionario Institucional (PRI) como un partido cercano al centro, con el Partido Acción Nacional (PAN) a la derecha y al Partido de la Revolución Democrática (PRD) a la izquierda, conformándose la coalición mayoritaria gobernante entre el PRI y PAN y en la oposición al PRD. La segunda dimensión referencia al eje democracia-autoritarismo, donde el PAN estaría ubicado en un punto intermedio del continuum, con el PRD como la agrupación más próxima y el PRI como el partido más alejado, donde este último lideraría el bloque opositor y los dos primeros serían base de la coalición mayoritaria de gobierno (Magaloni 2006; Greene 2007; Rosas 2010).

La adscripción a la coalición mayoritaria de gobierno dotaría a sus miembros de mayores de probabilidades de impulsar exitosamente sus políticas, mientras que la pertenencia al bloque opositor disminuiría tales probabilidades. Las coaliciones en las legislaturas LXI, LXII y LXIII fueron PAN y PRI con el 70, 58 y $75 \%$ de ocurrencia, respectivamente (Knight 2018: 21), mientras que PAN y PRD ocurrieron el 15, 20 y 11 \% de las veces. El Partido Verde Ecologista de México (PVEM) se incorporó a la coalición con el PRI en el 14 \% de las veces en la LXI Legislatura (2009-2012), mientras que la coalición entre el PRI-PVEM y la Nueva Alianza (NA) tuvo lugar el 22 y $14 \%$ de las veces en las legislaturas LXII y LXIII ${ }^{3}$ (Knight 2018: 21). Resulta interesante observar que la coalición PAN-PRDPVEM solo ocurrió en menos del uno por ciento de las ocasiones durante la LXII Legislatura. De lo anterior se desprende que las principales coaliciones fueron PAN-PRI Y PAN-PRD. La hipótesis a verificar es la siguiente:

H1 Los legisladores pertenecientes a la coalición mayoritaria de gobierno tendrán más probabilidades de promover exitosamente sus políticas en comparación con los de tendencia opositora.

Asimismo, diversas aproximaciones teóricas proyectan a las comisiones como instituciones con implicaciones esenciales en el funcionamiento del Congreso. Desde la perspectiva que enfatiza en el rol de los partidos, las comisiones ocupan un lugar importante, pero influidas por los acuerdos y directrices del conglomerado político. Krehbiel (1991) propone un acercamiento distinto, surgido de su análisis sobre el Congreso de EE. UU. en base a la concentración de información que desarrollan los integrantes de las comisiones para tratar temas específicos. Gran parte de los datos acumulados por los legisladores deriva de

Las legislaturas LXII y LXIII del Congreso de la Unión de México corresponden a los periodos entre el 1 de septiembre de 2012 concluyendo el 31 de agosto de 2015 y el 1 de septiembre de 2015 concluyendo el 31 de agosto de 2018, respectivamente. 
las ventajas proporcionadas por el seniority system, que los lleva a especializarse en materias propias de sus jurisdicciones y en comisiones en las que llevan participando largo tiempo, donde la antigüedad es el criterio para asignar los puestos de autoridad en ellas.

Sin embargo, en casos como el mexicano - de prohibición de reelección consecutiva-, se genera un contexto legislativo distinto al estadounidense. Aparicio y Langston (2009), refiriéndose a este contexto, argumentan que los dirigentes partidistas distribuyen puestos de autoridad en las comisiones según dos objetivos: 1) regular el flujo y contenido de las propuestas legislativas a votarse en el pleno, para que satisfagan intereses del partido y de liderazgos locales, y 2) coadyuvar en las labores de coordinación del grupo parlamentario. Para el cumplimiento de estos objetivos, la designación recae en agentes leales que eviten pérdidas en el proceso de delegación, quienes se ubicarán en una posición de liderazgo e influencia institucional. De ahí la relevancia de analizar los perfiles de quienes se posicionan en los puestos de autoridad en comisiones.

Los líderes de conglomerados políticos mantienen a su disposición variada información respecto de las cualidades de cada integrante - entre la que se incluye, al menos, la trayectoria político-partidista, en la administración pública y el nivel de educación-, la que puede ser utilizada para designar a quienes ocuparán cargos de autoridad. De este modo, la hipótesis respecto de la nominación de puestos de autoridad en las comisiones es la siguiente:

H2 A más experiencia profesional y política, mayores probabilidades que la o el legislador alcance un puesto de autoridad en una comisión.

Por otra parte, el diseño institucional de México es un atractivo caso de estudio para explorar la relación entre la prohibición de reelección consecutiva y un sistema electoral mixto. Diversos investigaciones sostienen que legisladores electos por el principio de mayoría relativa dedican esfuerzos considerables en labrarse un prestigio personal que les reditúe electoralmente. Para lograr tal fin, estos parlamentarios participan en múltiples actividades en el Congreso tendentes a promover su imagen pública y los intereses del distrito geográfico por el cual fueron electos, con el objetivo de expandir su núcleo de votantes (Shugart y Carey 1992; André et al. 2004). En contraste, congresistas electos a través del principio de representación proporcional estarían defendiendo intereses nacionales y los vinculados al partido. Ahora bien, dada la existencia en la realidad legislativa mexicana de un sistema electoral mixto, se esperaría observar un balance entre los espacios de liderazgo ocupados por diputados de mayoría relativa y representación proporcional, así como en su capacidad para promover intereses.

Sin embargo, la prohibición de la reelección consecutiva en México podría contravenir los efectos esperados sobre los sistemas electorales mixtos. El hecho 
de que factores locales deleguen en los liderazgos partidistas ${ }^{4}$ nacionales su relación con la Cámara de Diputados y la presencia de modelos centralizados de partido (esto es, con influencia para nominar a los candidatos electos por el principio de representación proporcional), podría potenciar la presencia y éxito en la promoción de sus políticas de legisladores electos por este principio y marginar a quienes provienen de mayoría relativa. Al respecto, se propone la siguiente hipótesis:

H3 Los legisladores electos por el principio de representación proporcional ocuparán más espacios de liderazgo y obtendrán más éxitos en la promoción de sus políticas.

Otro factor mencionado por múltiples estudios como desencadenante de asimetrías es el género. Heath et al. (2005) argumentan que cuando un grupo emergente dentro una comunidad se encuentra en crecimiento, el círculo dominante adoptará estrategias para marginarlo de los espacios de liderazgo. Para comprobar esta idea estudiaron la ubicación en comisiones de las legisladoras de Venezuela, Costa Rica, Colombia, Chile, Honduras y Argentina. Los hallazgos de su estudio apuntan hacia una sobrerrepresentación de las parlamentarias en comisiones cuyas materias son los temas sociales y los relativos al género, acompañados de una infrarrepresentación en aquellas con mayor poder, como las que tratan aspectos económicos, relaciones internacionales y de gobierno.

Si bien es cierto que las senadoras y diputadas mexicanas han ido ganando más espacios de representación en el Congreso, no cuentan con iguales probabilidades para ocupar posiciones de liderazgo que los hombres. México adoptó una ley de cuotas en 2002, la que consideró como piso el 30 \% de candidatas y una de cada tres candidatos por el principio de representación proporcional. En 2008 se amplió a 40 \% las candidaturas destinadas a mujeres y se incluyó una conformación alternada entre géneros para las listas de candidatos por el principio de representación proporcional ${ }^{5}$. Durante 2014, en tanto, se aprobó una nueva reforma que obliga a los partidos políticos a asegurar la paridad de género —es decir, $50 \%$ de nominaciones para hombres y mujeres por igual-y que las candidatas no fueran registradas exclusivamente en distrito perdedores.

Es así como se observa que la proporción de diputadas se ha incrementado gradualmente: de un 11,8 \% en 1988 al 17,2 \% en 1997, porcentaje que llegó a un $23 \%$ en 2003 y continuó incrementándose hasta llegar a un $37 \%$ en 2012 y un 48,2 \% en 2018 (Rodríguez 2003: 141-142; Piscopo 2014: 90; Cámara de Diputados 2018). En el continente americano estos cambios han avanzado desde el 12,7 \% en 1995 a un 30,7 \% en 2018 (Inter-Parliamentary Union-IPU

En este trabajo se entiende por liderazgos partidistas a aquellos integrantes de los consejos ejecutivos partidistas de los ámbitos estatal y nacional.

Esta reforma, sin embargo, no contempló que los suplentes de candidatos fueran del mismo género que los titulares, ocasionando que algunas parlamentarias electas renunciaran a favor de su reemplazo masculino, quienes son conocidas como “juanitas" (Aparicio y Langston 2009). 
2019: 2). Esta progresiva ampliación de la representación de parlamentarias en el Congreso - siguiendo los estudios sobre la marginación de la mujer - podría generar una estrategia por parte de los grupos dominantes por relegarlas de los espacios de liderazgo, en virtud que su arribo pareciera potenciado debido a la ley. Partiendo de esta premisa, se propone la siguiente hipótesis a validar:

H4 Las legisladoras enfrentarán mayores dificultades para promover exitosamente sus intereses y para ocupar espacios de liderazgo en comparación con sus colegas hombres.

\section{METODOLOGÍA}

Para verificar la validez de estas hipótesis se recabó información a nivel individual de la Cámara de Diputados entre 2009 y 2016. Este periodo abarca las legislaturas LXI, LXII y LXIII. Si bien este órgano consta de quinientos integrantes - trescientos electos por el principio de mayoría relativa y doscientos por el de representación proporcional- con renovación total cada tres años, la base de datos está conformada por 1520 integrantes debido a algunas sustituciones.

La información codificada para cada integrante comprende la cantidad de iniciativas que logró aprobar, las comisiones (comisiones ordinarias) a las cuales pertenece y si preside o no alguna de éstas. Para comprobar H1 y H3, la variable dependiente es la proporción de «iniciativas aprobadas» sobre las «presentadas», resultando una variable de conteo $^{6}$ que permitirá identificar las adscripciones partidistas de la coalición mayoritaria gobernante tendiente a manejar la producción legislativa. Por otra parte, una de las estrategias que pueden adoptar los legisladores para establecer vínculos con su núcleo de electores -y ampliarlo- es presentar una numerosa cantidad de iniciativas. Como variable de control de esta estrategia se agrega la cifra total de «iniciativas introducidas» por cada legislador. Como control también se incluye una variable para captar si la «legislatura coincide con la etapa de renovación del Ejecutivo o no», ya que diversos estudios han identificado que en aquellos periodos en que no se realiza un cambio en la Presidencia de la República, suelen aprobar más proyectos de ley, la cual es codificada como "legislatura no electoral" (Fernández-Albertos y Lapuente 2010).

En el análisis correspondiente a $\mathrm{H} 2$ y H4, la variable dependiente es dicotómica, donde 1 equivale a «presidente de comisión» y 0 a «cualquier otro puesto». Las presidencias de las comisiones son puestos valiosos, pues implican contar con recursos monetarios y humanos, convocar y dirigir sesiones de trabajo y ubicarse en una posición que facilita las relaciones con otros liderazgos partidistas,

Se recabaron las iniciativas presentadas y aprobadas para el periodo íntegro de las legislaturas LXI y LXII. Por otra parte, para la LXIII Legislatura — que comenzó el 1 de septiembre de 2015 y finalizó el 31 de agosto de 2018- solo se recabaron las iniciativas aprobadas y presentadas hasta agosto de 2016. Para el modelo de proporción de iniciativas aprobadas sobre presentadas solo se incluyó a quienes presentaron alguna iniciativa. 
medios de comunicación y poseer la capacidad de distribuir beneficios, lo que incrementa las probabilidades de escalar en una carrera política.

Asimismo, se creó una variable dicotómica donde 1 equivale a «pertenece» y 0 a «no pertenece» en relación a quienes integran alguna de las comisiones con trascendencia en el Congreso mexicano. Alemán (2008) reconoce que la gran mayoría de estas instancias en los parlamentos de América Latina se encuentran lejos de asemejarse a sus pares estadounidenses, en cuanto a los recursos que manejan, a su autonomía y a la determinación sobre los procesos legislativos. Este autor, sin embargo, observó a un selecto grupo de comisiones - usualmente vinculadas a temas clave como los de Hacienda, asuntos constitucionales y de gobierno-, conformadas por líderes políticos experimentados, quienes facilitan la coordinación de estos sensibles temas recurrentes de la agenda pública. Para el caso mexicano, Vázquez (2017) identificó asimetrías de influencia entre unas y otras comisiones de la Cámara de Diputados, ya que tan solo unas cuantas participaron constantemente en el análisis y modificación de las iniciativas que envió el Ejecutivo. Esta investigación, por su parte, se basa en la propuesta de clasificación de Frisch y Kelly (2004), la cual permite distinguir a las comisiones de relevancia - en cuanto a los temas que tratan- de aquellas que están enfocadas a políticas que inciden en grupos específicos, con modificaciones para su aplicación al caso que aquí se analiza7 .

Las variables explicativas fueron codificadas de la siguiente forma. Para identificar el método de elección se incluye como variable dicotómica $1=$ «mayoría relativa» y $0=$ «representación proporcional». Con esta variable se podrá comprobar si la prohibición de reelección en México contraviene los efectos del principio mayoría relativa tendentes a incrementar los esfuerzos individuales por labrarse un prestigio personal a través del impulso de iniciativas de ley. Por otra parte, el «género» también es captado a través de una variable dicotómica donde $1=$ «mujer» y $0=$ «hombre». Esta variable reflejaría las posibles desventajas que perjudican a este grupo de la población al ocupar o no posiciones de liderazgo en el sistema de comisiones y ubicarse en los márgenes de aquellas que son más relevantes.

La información sobre «afiliación partidista» fue captada a través de variables dicotómicas y permitirá verificar la H1. Se incluyeron los partidos PAN, PRI y PRD. El PVEM también fue introducido en el modelo ya que, a lo largo del periodo de estudio, fue una agrupación política que actuó de manera coordinada con el PRI en el Congreso. También se introdujo al Movimiento Regeneración Nacional

Las legislaturas LXI, LXII y LXIII organizaron su sistema de comisiones en 44, 56 y 56 comisiones ordinarias, respectivamente. Por su parte, basándose en esta propuesta de Frisch y Kelly (2004), la cual distingue las comisiones que analizan políticas concretas, con incidencia en grupos o clientelas específicas, de aquellas con un margen de impacto general y mayor prestigio y relevancia, son clasificadas las comisiones. Para este último grupo, las comisiones ordinarias incluidas son las siguientes: 1) Hacienda y Crédito Público; 2) Presupuesto y Cuenta Pública; 3) Economía, Comercio y Competitividad; 4) Justicia; 5) Derechos Humanos; 6) Gobernación y Población; 7) Seguridad Pública; 8) Defensa Nacional; 9) Marina; 10) Puntos Constitucionales; y 11) Relaciones Exteriores. 
(MORENA), el cual ha aumentado sustancialmente su capacidad aglutinante de legisladores de izquierda. Toda esta información permitirá identificar la adscripción partidista de la coalición mayoritaria gobernante tendente a controlar la producción legislativa, cuyos integrantes tendrían mayores probabilidades de promover exitosamente sus políticas.

La variable relativa a la "formación» de cada integrante fue constituida de cuatro conjuntos. De este modo, el nivel educativo incluye: a) licenciatura trunca, preparatoria o menores grados de estudio, lo cual sirve como categoría de referencia; b) formación técnica o normalista; c) licenciatura o ingeniería completa; y d) estudios de posgrado. Este grupo de variables capta la formación de los legisladores asumiendo que quienes cuentan con mejor formación ejercerían a su vez una mayor influencia y, por ende, tendrían superiores probabilidades de ocupar espacios de liderazgo en el Congreso.

En tanto la serie de variables que captan la «trayectoria en altos puestos políticos» de la administración pública fueron organizadas como sigue: a) sin experiencia, utilizada como categoría de referencia; b) trayectoria en la administración local, ya sea en regiduría, presidencia municipal, integrante del Gabinete Estatal o titular del Poder Ejecutivo de la entidad federativa; c) trayectoria en la administración federal, ya sea secretaría o subsecretaría o en la dirección de algún organismo descentralizado; y d) experiencia en algunos de estos puestos tanto a nivel local como federal.

El conjunto de variables que captan la «trayectoria partidista» es: a) sin trayectoria partidista, que sirve como categoría de referencia; b) presidencia de partido a nivel estatal, secretaría del partido o pertenencia al Consejo Ejecutivo Estatal; c) presidencia de partido a nivel nacional, secretaría del partido o integrante del Consejo Ejecutivo Nacional; y d) experiencia partidista en estos puestos para los ámbitos estatal y nacional.

Finalmente, las variables para captar la «experiencia legislativa» están organizadas como sigue: a) sin experiencia, lo cual funge como categoría de referencia; b) solo en el Congreso local, c) solo en el Congreso federal; y d) participación previa tanto en el Congreso local como en el federal o bien como integrante a nivel federal en dos o más legislaturas ${ }^{8}$.

Se estimaron tres modelos. Uno para analizar las iniciativas aprobadas de entre las presentadas mediante una estimación binomial negativa como modelo de conteo, que se deriva del promedio de la distribución Poisson en términos de un parámetro fijo; el cual, a su vez, se distribuye como una distribución gamma. Para los determinantes de presidir una comisión y pertenecer a una comisión relevante se emplearon modelos logísticos binarios. Finalmente se agregaron

8 La tabla 3, en Anexo, presenta la estadística descriptiva y en el anexo se incluyen ocho gráficas comparando género y método de elección según las diversas trayectorias. 
simulaciones con la predicción de probabilidades de las variables explicativas de interés para cada una de las variables dependientes.

\section{RESULTADOS}

La tabla 1 contiene los resultados de los tres modelos. En el modelo de proporción de iniciativas aprobadas sobre presentadas, las variables partidistas muestran significancia estadística positiva, lo cual subraya la importancia de la coordinación partidista en la aprobación de políticas. La adscripción partidista al PAN y PRI también muestra una relación positiva con relevancia estadística, que puede sugerir mayores intercambios y apoyos entre tales integrantes.

Tabla 1. Determinantes de poder e influencia en el Congreso mexicano

\begin{tabular}{|c|c|c|c|c|c|c|}
\hline & \multicolumn{2}{|c|}{$\begin{array}{l}\text { Proporción de inicia- } \\
\text { tivas aprobadas sobre } \\
\text { presentadas }\end{array}$} & \multicolumn{2}{|c|}{ Presidencia de comisión } & \multicolumn{2}{|c|}{ Comisiones relevantes } \\
\hline & Coeficiente & $\begin{array}{l}\text { Error esta- } \\
\text { dístico }\end{array}$ & Coeficiente & $\begin{array}{l}\text { Error esta- } \\
\text { dístico }\end{array}$ & Coeficiente & $\begin{array}{l}\text { Error esta- } \\
\text { dístico }\end{array}$ \\
\hline Mujer & 0,05 & 0,06 & $-0,475^{* *}$ & 0,18 & $-0,41^{* *}$ & 0,11 \\
\hline $\begin{array}{l}\text { Mayoría } \\
\text { relativa }\end{array}$ & $-0,19^{* *}$ & 0,07 & $-0,296$ & 0,17 & $-0,53^{* *}$ & 0,11 \\
\hline $\begin{array}{l}\text { Presidente de } \\
\text { comisión }\end{array}$ & $0,53^{* *}$ & 0,09 & & & & \\
\hline $\begin{array}{l}\text { Legislatura no } \\
\text { electoral }\end{array}$ & $0,36^{* *}$ & 0,06 & & & & \\
\hline PVEM & $0,85^{* *}$ & 0,16 & & & & \\
\hline MORENA & $-0,14$ & 0,22 & & & & \\
\hline PRD & 0,20 & 0,10 & & & & \\
\hline PAN & $0,88^{* *}$ & 0,12 & & & & \\
\hline PRI & $1,0^{* *}$ & 0,64 & & & & \\
\hline $\begin{array}{l}\text { Iniciativas } \\
\text { presentadas }\end{array}$ & $0,01 *$ & 0,001 & & & & \\
\hline $\begin{array}{l}\text { Partido político } \\
\text { en gobierno }\end{array}$ & & & 0,046 & 0,17 & $-0,07$ & 0,11 \\
\hline $\begin{array}{l}\text { Técnico } \\
\text { profesional }\end{array}$ & 0,09 & 0,15 & $-0,31$ & 0,52 & $-0,85^{* *}$ & 0,27 \\
\hline Licenciatura & 0,06 & 0,11 & 0,38 & 0,32 & 0,14 & 0,17 \\
\hline Posgrado & $-0,05$ & 0,12 & $0,74^{*}$ & 0,33 & $0,82^{* *}$ & 0,19 \\
\hline $\begin{array}{l}\text { Legislador } \\
\text { local }\end{array}$ & $-0,22 * *$ & 0,07 & $-0,17$ & 0,21 & $-0,01$ & 0,13 \\
\hline $\begin{array}{l}\text { Legislador } \\
\text { nacional }\end{array}$ & $-0,04$ & 0,13 & 0,31 & 0,31 & $-0,03$ & 0,22 \\
\hline
\end{tabular}




\begin{tabular}{|c|c|c|c|c|c|c|}
\hline & \multicolumn{2}{|c|}{$\begin{array}{l}\text { Proporción de inicia- } \\
\text { tivas aprobadas sobre } \\
\text { presentadas }\end{array}$} & \multicolumn{2}{|c|}{ Presidencia de comisión } & \multicolumn{2}{|c|}{ Comisiones relevantes } \\
\hline & Coeficiente & $\begin{array}{l}\text { Error esta- } \\
\text { dístico }\end{array}$ & Coeficiente & $\begin{array}{l}\text { Error esta- } \\
\text { dístico }\end{array}$ & Coeficiente & $\begin{array}{l}\text { Error esta- } \\
\text { dístico }\end{array}$ \\
\hline $\begin{array}{l}\text { Legislador } \\
\text { nacional y local }\end{array}$ & 0,11 & 0,09 & $0,46^{*}$ & 0,23 & $-0,08$ & 0,17 \\
\hline $\begin{array}{l}\text { Líder partido } \\
\text { local }\end{array}$ & $-0,02$ & 0,08 & 0,09 & 0,23 & 0,17 & 0,14 \\
\hline $\begin{array}{l}\text { Líder partido } \\
\text { nacional }\end{array}$ & $-0,31^{* *}$ & 0,12 & $0,55^{*}$ & 0,28 & 0,25 & 0,20 \\
\hline $\begin{array}{l}\text { Líder partido } \\
\text { nacional y local }\end{array}$ & $-0,22$ & 0,08 & $0,42^{*}$ & 0,21 & 0,14 & 0,14 \\
\hline $\begin{array}{l}\text { Administración } \\
\text { pública local }\end{array}$ & $-0,01$ & 0,79 & $-0,11$ & 0,17 & $-0,01$ & 0,11 \\
\hline $\begin{array}{l}\text { Administración } \\
\text { pública } \\
\text { nacional }\end{array}$ & $-0,02$ & 0,90 & 0,36 & 0,41 & $0,67^{*}$ & 0,38 \\
\hline $\begin{array}{l}\text { Administración } \\
\text { pública } \\
\text { nacional y local }\end{array}$ & 0,06 & 0,85 & $1,24^{* *}$ & 0,52 & 0,65 & 0,51 \\
\hline Constante & & $1,597^{* *}$ & & $-2,37^{* *}$ & & 0,21 \\
\hline $\begin{array}{l}\text { Razón de } \\
\text { verisimilitud }\end{array}$ & & $226946^{* *}$ & & & & \\
\hline R2 ajustada & & 0,03 & & 0,072 & & 0,09 \\
\hline Observaciones & & 1240 & & 1508 & & 1508 \\
\hline Modelo & Binon & ial negativo & & Logístico & & Logístico \\
\hline
\end{tabular}

Notas: *p. $<0,05 ;{ }^{* *}$ p. $<0,01$

Fuente: estimación de los autores con información del banco de datos legislativos ITESM-FEMS

Los resultados sugieren que, a lo largo de este periodo, la afiliación política de la coalición mayoritaria gobernante tendente a controlar la producción legislativa colocó a los legisladores del PAN y el PRI en posición de promover con mayor éxito sus intereses, lo que coincide con la H1. Otro partido con significancia estadística positiva es el PVEM, el cual a lo largo de estos años en estudio fue aliado frecuente del PRI. Por su parte los legisladores del PRD, aunque muestran una relación positiva, esta no es estadísticamente significativa; es decir, los parlamentarios del PRD fueron menos exitosos que sus pares del PRI y PAN.

Los congresistas electos por el principio de mayoría relativa están negativamente vinculados con la promoción exitosa de iniciativas de leyes. Lo anterior muestra que la votación a través de representación proporcional revela una incidencia positiva en la promoción exitosa de las políticas, lo que a su vez valida la H3. El presidir una comisión también muestra una relación estadística significativa sobre los éxitos legislativos, lo cual sugiere que tanto los presidentes de comisión como los diputados electos por el principio de representación proporcional tienen ventajas derivadas de sus vínculos con los líderes nacionales de los 
partidos. La variable de control - legislatura no electoral, es decir no coincidente con la renovación del Ejecutivo- muestra un signo consistente con anteriores trabajos, subrayando el impacto del ciclo electoral en la producción de leyes.

En el modelo de presidencia de comisión se observa que los parlamentarios con experiencia local y nacional en el ámbito legislativo y en altos puestos de la administración pública son quienes tienen mayores probabilidades de ubicarse en estas posiciones de autoridad, resultado que está en línea con la H2. Esta trayectoria de escalamiento desde lo local a lo nacional, como se muestra en el anexo, fue alcanzada por el $14 \%$ de los congresistas en el ámbito legislativo, mientras que en el ámbito de la administración pública apenas el 1 \% contó con ese recorrido. Asimismo, en todos los modelos, la trayectoria local — tanto en los ámbitos legislativo como en la administración pública- muestra un signo negativo, aunque no es estadísticamente significativo. Los resultados sugieren que contar solamente con experiencia local en alguno de estos rubros de acción parece no representar ventajas.

Sin embargo, la experiencia en el ámbito nacional representa claras ventajas para ocupar una presidencia de comisión en las trayectorias en dirigencias partidistas, aunque para obtener tales beneficios no es indispensable escalar desde lo local a la nacional, como sí ocurre en las trayectorias legislativas y de administración pública. Es más, a diferencia de los otros dos rubros, contar con experiencia en el ámbito partidista local también genera algunas ventajas para ocupar una presidencia de comisión, como lo muestra el signo positivo del coeficiente. Estos resultados subrayan nuevamente la importancia de contar con vínculos con los líderes de los conglomerados políticos para lograr la postulación a través del principio de representación proporcional y posteriormente acceder a los cargos de dirigencia en el sistema de comisiones.

Por contraparte, la variable mujer presenta una asociación negativa y con fuerza estadística respecto a su posicionamiento en espacios de liderazgo, avalando la $\mathrm{H}^{9}$. Del mismo modo, la elección de integrantes del Congreso por el principio de mayoría relativa, aunque carece de fuerza estadística, también está asociada negativamente con su ubicación en la presidencia de comisiones.

En cuanto a los resultados del modelo que muestra las relaciones entre diversas variables con la pertenencia a comisiones relevantes, sostienen algunas similitudes con los del modelo de presidencia de comisión. Nuevamente aparecen las variables mujer y de mayoría relativa con impacto negativo y significancia estadística, respaldando las $\mathrm{H} 3$ y H4. Si bien las variables relativas 
a las trayectorias de los legisladores pierden fuerza estadística, varias conservan el signo en la misma dirección que el modelo de presidente de comisión, salvo las categorías correspondientes a la experiencia legislativa.

El pronóstico del impacto de algunas de las variables que resultaron estadísticamente significativas en cada uno de los tres modelos se presenta en los próximos gráficos 1, 2 y 3 . Se observa, por ejemplo, que la probabilidad de presidir una comisión es de $8 \%$ entre mujeres y $12 \%$ entre hombres, mientras que para integrar una comisión relevante dicho porcentaje se reparte en un 55 $\%$ para hombres y el $44 \%$ restante para mujeres. Asimismo se aprecia que la probabilidad de integrar alguna comisión relevante entre quienes compitieron por mayoría relativa es del $46 \%$, mientras que entre quienes llegaron a Cámara por lista dicho porcentaje se amplía a un $59 \%$.

Gráfico 1. Pronóstico del porcentaje de iniciativas aprobadas

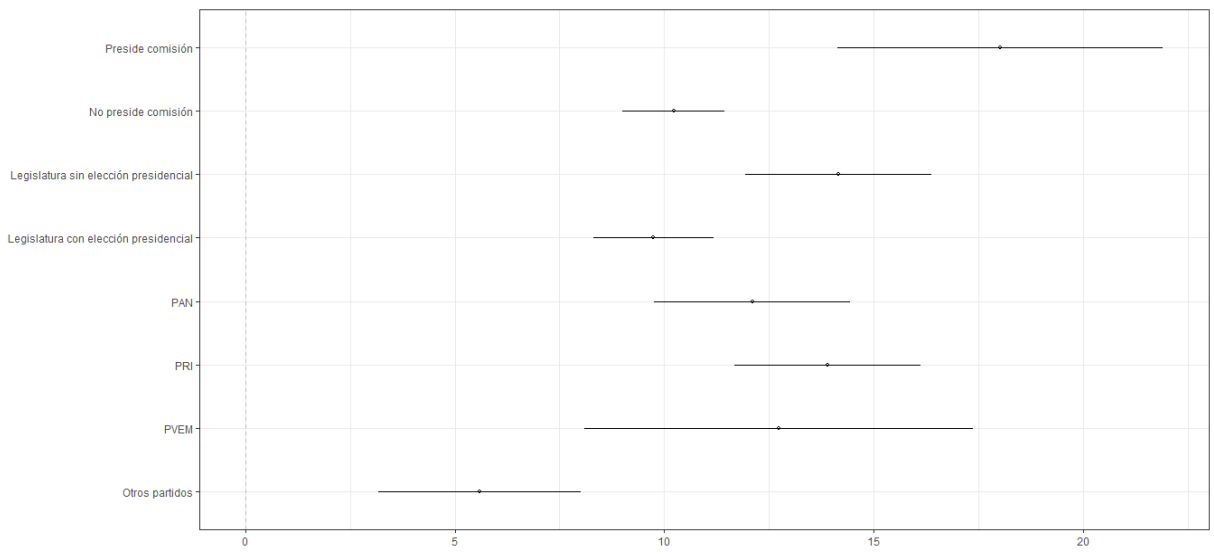

Fuente: modelo 1. Se muestran algunas variables significativas, intervalos al $95 \%$. Eje horizontal: porcentaje de iniciativas aprobadas 


\section{Gráfico 2. Pronóstico para presidencia de comisión}

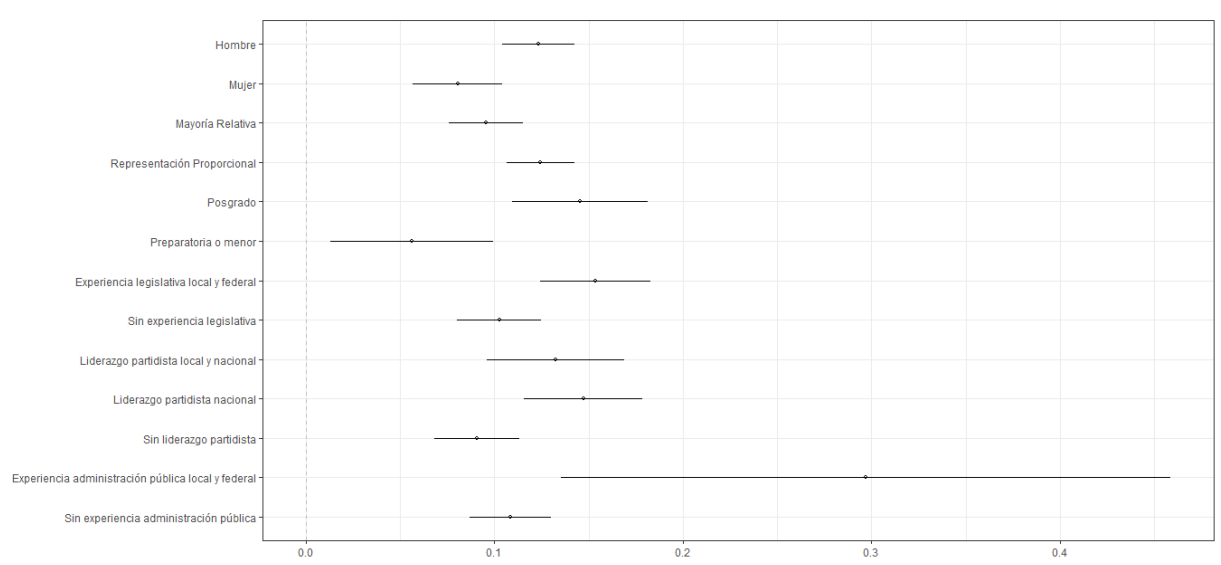

Fuente: modelo 2. Se muestran algunas variables significativas, intervalos al $95 \%$. Eje horizontal: probabilidad de presidir comisión

Gráfico 3. Pronóstico para integrar una comisión relevante

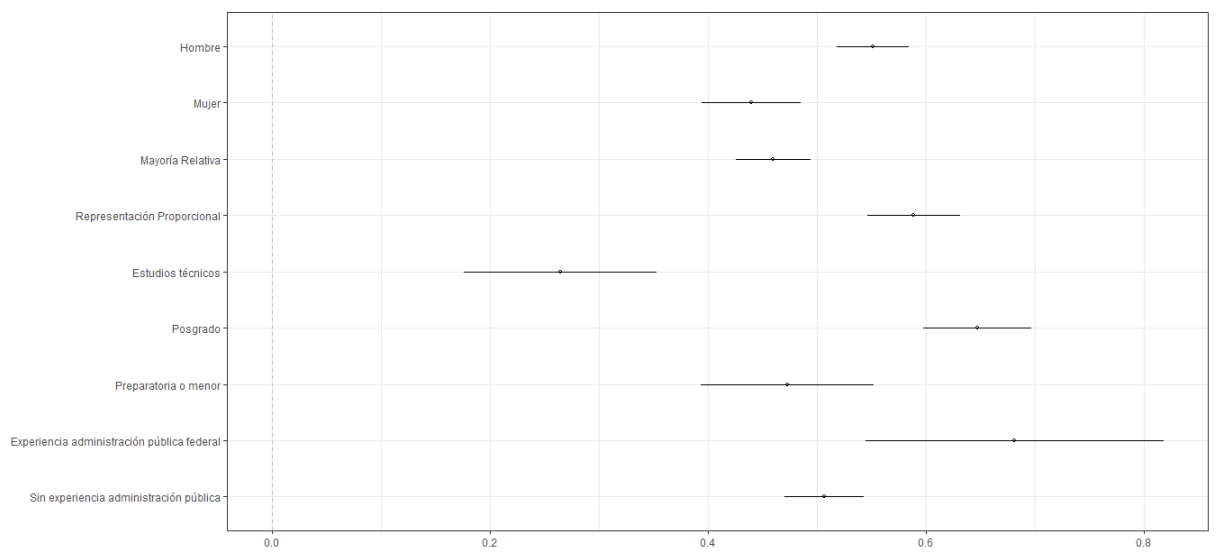

Fuente: modelo 3. Se muestran las variables significativas, intervalos al $95 \%$. Eje horizontal: probabilidad de integrar comisión relevante.

Por otra parte, la tabla 2 muestra las diferencias en las proporciones de los espacios con representación para mujeres y los legisladores electos por el principio de mayoría relativa. Se observa que la proporción de presidencias de comisiones que se ocuparon entre 2009 y 2016 se modificó sustancialmente, quizá derivado de las cuotas de 2008 - ya en marcha para la LXI Legislatura- y de la 
paridad aprobada en 2014 — que surtió efectos en la LXIII Legislatura-. Pero, al mismo tiempo, se aprecia un crecimiento en las diferencias entre representación y posiciones de liderazgo ocupados por diputadas.

Tabla 2. Representación en legislaturas por género y método de elección, 2009-2016

\begin{tabular}{lccc}
\hline & $\begin{array}{c}\text { Proporción } \\
\text { representación } \\
\text { en Cámara de } \\
\text { Diputados }\end{array}$ & $\begin{array}{c}\text { Proporción } \\
\text { ocupando } \\
\text { presidencias de } \\
\text { comisión }\end{array}$ & $\begin{array}{c}\text { Diferencia entre } \\
\text { ambas proporciones }\end{array}$ \\
\hline Mujer & 0,27 & 0,20 & $-0,07$ \\
LXI & 0,36 & 0,27 & $-0,09$ \\
LXII & 0,41 & 0,32 & $-0,09$ \\
LXIII & & & $-0,12$ \\
Mayoría relativa & 0,60 & 0,48 & $-0,10$ \\
LXI & 0,60 & 0,50 & $-0,05$ \\
LXII & 0,60 & 0,55 & \\
LXIII & & & \\
\hline
\end{tabular}

Fuente: elaboración de los autores con información del banco de datos legislativos itesm-femsa

Del mismo modo, los diputados electos por mayoría relativa muestran una desproporción importante entre su representación en la Cámara de Diputados y la correlación de espacios de liderazgo en comisiones. La otra cara de esta moneda es la sobrerepresentación de legisladores nominados por representación proporcional en las presidencias de las comisiones reflejo de su vínculo con los líderes partidarios.

Por otra parte, a partir del cálculo de los efectos de las trayectorias partidistas en la probabilidad de ocupar alguna presidencia de comisión y manteniendo los valores de las demás variables en su equivalencia promedio, se observa que - como lo muestra el gráfico 4- la experiencia al interior del partido tiende a beneficiar en la misma proporción a los legisladores electos por ambos principios. Sin embargo, para el caso de la variable género, los vínculos con las dirigencias generan mayores ventajas para varones, aunque para ambos grupos es redituable la experiencia previa ${ }^{10}$.

10 En el anexo se muestran las gráficas de la relación entre género y métodos de elección según trayectorias. Con el objetivo de identificar diferencias entre grupos se realizaron pruebas U de Mann-Withney para distribuciones no paramétricas, recodificando las trayectorias en valores numéricos. Los resultados no arrojaron 
Gráfico 4. Efectos de género y método de elección para presidir una comisión
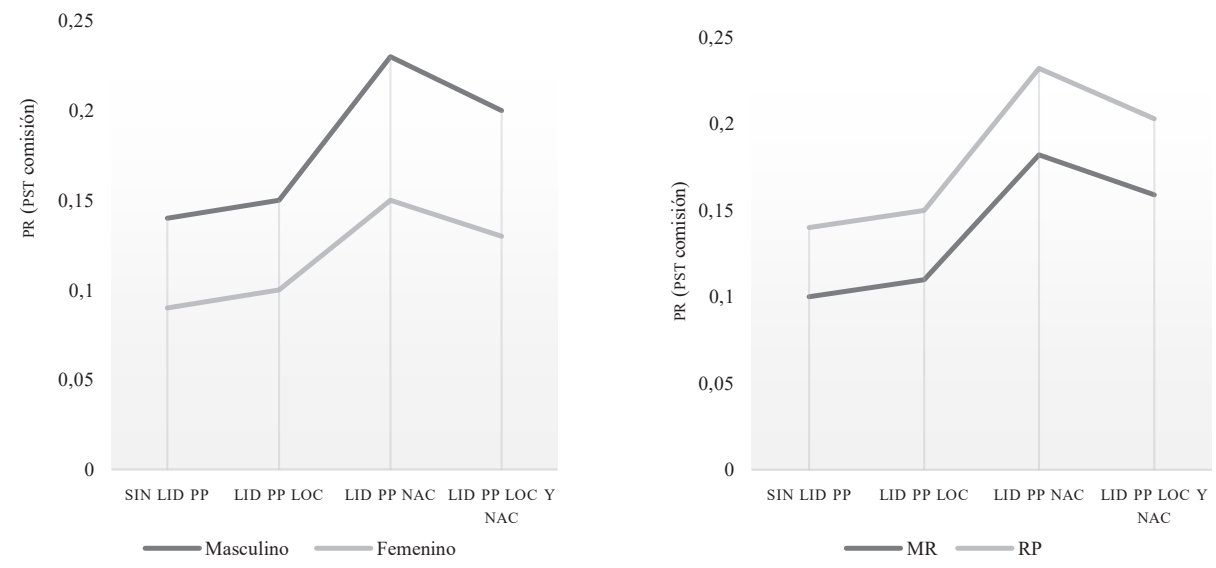

Fuente: modelo 2. Se muestran probabilidades de presidir comisión según categorías de liderazgo partidista por género (izquierda) y por método de elección (derecha).

Estos hallazgos contrastan con los resultados de Kerevel y Atkeson (2013). Su incluye la L Legislatura (2000 a 2003, periodo sin cuota de género obligatoria) y las legislaturas LI y LII (2003 al 2006 y 2006 al 2009, que incluyen la primera medida obligatoria de cuotas de género), y en el cual no encuentra evidencia para sustentar la hipótesis que predice marginación de las integrantes de la Cámara. Por el contrario, los resultados aquí presentados muestran que, conforme se incrementa la presencia de las mujeres, más se les encuentra en los márgenes de las posiciones de liderazgo del sistema de comisiones y de pertenencia a comisiones relevantes.

Por otra parte, los resultados de este trabajo son consistentes con los encontrados por Ugues Jr et al. (2012: 107). Su estudio muestra "evidencia frágil", pero en la dirección esperada entre el principio de elección y de ocupar una posición de liderazgo en comisión; ello respecto al tipo de comisión a la que pertenecen los integrantes de la Lx Legislatura. En el presente trabajo, al incluir un número mayor de casos, se ha fortalecido ligeramente la relación entre el principio de elección y el ocupar un puesto de liderazgo en comisiones además de pertenecer a una comisión relevante.

Asimismo, a diferencia de Kerevel (2010), el análisis de Ugues Jr et al. (2012) incluye variables relativas a la trayectoria de los legisladores, subrayando la importancia de la experiencia legislativa y en la administración pública en el ámbito nacional. Sus resultados son coincidentes con los aquí presentados. No 
obstante las variables relativas a las trayectorias en dirigencias partidistas del ámbito nacional aquí incluidas mostraron relevancia estadística para presidencia de comisión, no fue así para el modelo de comisiones relevantes, aunque con signo positivo. En conjunto, esta evidencia sugiere que ser dirigente de un partido juega un papel crucial en la distribución de posiciones de liderazgo e influencia en el Congreso ${ }^{11}$.

\section{VII.CONSIDERACIONES FINALES}

En América Latina, región donde la rotación legislativa es alta y la "conexión electoral" propuesta por Mayhew se encuentra intermediada por los partidos políticos, los criterios de distribución de posiciones de liderazgo e influencia van más allá de las normas de operación interna de los parlamentos. Aquí se han explorado los determinantes de la distribución de estos espacios para el caso mexicano. Su análisis es atractivo ya que la rotación del Congreso como de cualquier otro puesto de elección hasta la reforma electoral 2014era total, puesto que la reelección consecutiva se encontraba hasta hace poco prohibida. México, además, cuenta con partidos políticos que siguen un modelo centralizado de organización, los cuales actúan en un sistema electoral mixto.

El aporte fundamental de este artículo es el análisis empírico sistemático de las trayectorias de los integrantes de las legislaturas LXI, LXII y LXIII. Se encontró que la experiencia previa es un determinante importante de la distribución de puestos de liderazgo en el Congreso. Específicamente, los hallazgos ponen de relieve la importancia de los vínculos partidistas: haber formado parte de las dirigencias partidista - ya sea nacional y, en menor grado, local—, así como haber sido electo por el principio de representación proporcional, otorgan ventajas para presidir alguna comisión o para ser parte de alguna relevante. Por el contrario, trayectoria en la administración pública local y en congresos locales no representan ventajas por sí solas, a menos que se cuente con experiencia en el ámbito nacional. La afiliación del legislador al PAN y PRI está positivamente relacionada con el éxito en la promoción de sus intereses desde la Cámara, lo que indicaría la conformación de una coalición mayoritaria gobernante compuesta por estos dos partidos tendente a controlar la producción de leyes.

El periodo de estudio que abarca este trabajo incluye la ampliación de la cuota de género hasta la paridad, lo cual produjo que poco a poco se expandiera

11 Para el modelo de presidencia de comisión se corrió un modelo controlando por efectos fijos por legislatura, resultando que ninguno de los resultados reportados en la tabla 2 varió en signo o significancia, emergiendo como significativa y positiva la LXII Legislatura (valor $\mathrm{t}=2,041$ ). Dichos efectos fijos también se incluyeron para el modelo de integración de comisiones relevantes, donde tampoco se presentaron cambios ni en signos ni en significancia de las variables reportadas (excepto la experiencia en la administración pública a nivel nacional, donde su valor t se redujo $(1,68)$. La legislatura que resultó negativa y significativa fue la LXIII. El mismo ejercicio se replicó para el modelo sobre iniciativas, resultando estable en comparación con lo aquí reportado y con la LXIII Legislatura como significativa y negativa. En los tres casos, la legislatura de referencia fue la LXI, manteniendo en este último modelo las variables dicotómicas que identifican a los partidos políticos (modelos no mostrados). 
la presencia de las mujeres en la Cámara de Diputados. Sin embargo, paradójicamente, este progresivo incremento trajo consigo un aumento en la desproporción entre mujeres legisladoras y aquellas que ocupan espacios de liderazgo de comisiones.

En su conjunto, estos hallazgos empíricos tienen tres implicancias teóricas. Primero, una parte de la literatura centrada en el análisis de los sistemas electorales mixtos predice que, en el ámbito legislativo, estos generarían una defensa e impulso de intereses geográficos, tanto locales como nacionales, lo cual podría observarse en un distribución semejante de los espacios de liderazgo entre parlamentarios electos por representación proporcional y mayoría relativa (Shugart y Carey 1992; André et al. 2004). Sin embargo, la introducción de un sistema de partidos centralizado y la prohibición de la reelección inmediata pareciera cuestionar los efectos predichos respecto los sistemas electorales mixtos. Aquí se ha dado cuenta que ocurre un desbalance a favor de los congresistas electos por el principio de representación proporcional.

Segundo, en este mismo ámbito, los hallazgos apuntan hacia que los vínculos con las dirigencias partidistas, las trayectorias de escalamiento desde lo local a lo nacional y de la administración pública son factores positivamente relacionados con el acceso a los espacios de liderazgo. De esta forma, los parlamentarios que carecen de estas trayectorias y que tengan en mente escalar hacia puestos de liderazgo posiblemente busquen construir carreras políticas semejantes a las trayectorias previamente mencionadas. En virtud de ello sería esperable observarles participando en procesos y posiciones que les permitan visibilizarse con los liderazgos locales (como enmiendas al presupuesto, comisiones específicas, entre otros), siempre congraciándose con los líderes nacionales de los partidos políticos. Mientras, los legisladores ya respaldados por estas trayectorias y electos vía representación proporcional se ubican en posiciones de liderazgo con interlocución con otras fuerzas políticas y visibilidad nacional, desde donde tendrán mayores probabilidades de ocupar posteriormente otra posición semejante, dada la prohibición de la reelección consecutiva. Estos resultados muestran que esta exclusión no solo matiza "la conexión electoral" propuesta por Mayhew, sino que pone de relieve los dos peldaños en que se entrelaza la política legislativa intermediada por los liderazgos partidistas.

Finalmente, más allá de la teoría, estos resultados tienen implicaciones importantes para el nuevo curso político iniciado en México en 2018. Las elecciones arrojaron dos resultados interesantes: por un lado, la conformación de la Cámara de Diputados por primera vez estuvo al borde de alcanzar la paridad (con el 48,2 \% de legisladoras) y, por otra, la fuerte irrupción de MORENA (con el 51,8 \% de los espacios en la Cámara de Diputados) y la disminución en la representación de legisladores del PRI y PAN, lo que trajo consigo que una gran cantidad de parlamentarios experimentados quedaran fuera del Congreso y a su vez que ingresara una cantidad importante de integrantes sin experiencia legislativa previa. 
Lo anterior permitirá que investigaciones futuras puedan verificar el papel que juegue la reelección consecutiva en el reparto de poder en la Cámara, puesto que, de reelegirse integrantes hoy novatos, debería esperarse que —al pasar a su segundo periodo- se conviertan en veteranos, probablemente alcanzando algunas posiciones de poder e influencia, aunque quizá limitados en su segundo periodo por su género y su método de selección, lo que permitirá verificar estos efectos en los periodos tercero y cuarto, que representan el número máximo de ocasiones en las cuales puede reelegirse cualquier integrante de la Cámara de Diputados en México a partir de 2018.

\section{REFERENCIAS}

Alemán, Eduardo. 2008. "Policy Gatekeepers in Latin American Legislatures". Latin American Politics and Society 2 (2): 74-92.

Amorim Neto, Octavio, Gary W. Cox y Mathew D. McCubbins. 2003. "Agenda Power in Brazil's Câmara Dos Deputados, 1989-98". World Politics 55 (4): 550-578.

André, Audrey, Sam Depauw y Matthew S. Shugart. 2004. "The Effect of Electoral Institutions on Legislative Behaviour". En The Oxford Handbook of Legislative Studies editado por Shane Martin, Thomas Saalfeld y Kaare W. Strøm. New York: Oxford University Press, 231-249.

Aparicio, Javier y Joy Langston. 2009. “Committe Leadership in Mexico's Chamber of Deputies, 1997-2006". Ponencia presentada en la 67"h Midwest Political Science Association National Conference, Chicago.

Béjar Algazi, Luisa. 2014. "Cuando el Ejecutivo es débil ¿Quién legisla en México?”. Política y Gobierno 21 (2): 325-347.

Bruhn, Kathleen y Steven Wuhs. 2016. “Competition, Decentralization, y Candidate Selection in Mexico". American Behavioral Scientist 60 (7): 819-836.

Cámara de Diputados. 2018. "Integración por género y Grupo Parlamentario". Recuperado el 20 de diciembre de 2018 de http:/ / sitl.diputados.gob.mx/LXIV_leg/cuadro_genero.php

Cheibub, José Antonio, Argelina Figueiredo y Fernando Limongi. 2009. "Political Parties and Governors as Determinants of Behavior of Brazilian Legislators". Latin American Politics and Society 51 (1): 1-30.

Cox, Gary W. 2006. "The Organization of Democratic Legislatures". En The Oxford Handbook of Political Economic, editado por Donald A. Wittman y Barry R. Weingast. New York: Oxford University Press, 141-161.

Cox, Gary W. y Mathew D. McCubbins. 1993. Legislative Leviathan. Party Government in the House. Oakland: University of Californa Press.

Crisp, Brian F., Maria C. Escobar-Lemmon, Bradford S. Jones, Mark P. Jones y Michelle M. Taylor-Robinson. 2004. "Vote-Seeking Incentives and Legislative Representation in Six Presidential Democracies". The Journal of Politics 66 (3): 823-846.

Crisp, Brian F., Maria C. Escobar-Lemmon, Bradford S. Jones, Mark P. Jones y Michelle M. Taylor-Robinson. 2009. "The Electoral Connection and Legislative Committees". The Journal of Legislative Studies 15 (1): 35-52.

Fernández-Albertos, José y Víctor Lapuente. 2010. “Doomed to Disagree? Party-Voter Discipline and Policy Gridlock under Divided Government". Party Politics 17 (6): 801-822.

Frisch, Scott A. y Sean Q. Kelly. 2004. "Self-Selection Reconsidered: House Committee Assignment Requests and Constituency Characteristics". Political Research Quarterly 57(2): 325-336.

Greene, Kenneth F. 2007. Why Dominant Parties Lose: Mexico's Democratization in Comparative Perspective. New York: Cambridge University Press. 
Heath, Roseanna Michelle, Leslie A. Schwindt-Bayer y Michelle M. Taylor-Robinson. 2005. "Women on the Sidelines: Women's Representation on Committees in Latin American Legislatures". American Journal of Political Science 49 (2): 420-436.

Inter-Parliamentary Union (IPU). 2019. "Women in Parliament in 2018. The Year in Review". Reports . Geneva: Inter-Parliamentary Union (IPU).

Jones, Mark P. y Wonjae Hwang. 2005. "Party Government in Presidential Democracies: Extending Cartel Theory beyond the U.S. Congress". American Journal of Political Science 49 (2): 267-282.

Kerevel, Yann P. 2010. “The Legislative Consequences of Mexico's Mixed-Member Electoral System, 2000-2009". Electoral Studies 29 (4): 691-703.

Kerevel, Yann P. y Lonna Rae Atkeson. 2013. "Explaining the Marginalization of Women in Legislative Institutions". The Journal of Politics 75 (4): 980-992.

Kikuchi, Hirokazu y Germán Lodola. 2014. "The Effects of Gubernatorial Influence and Political Careerism on Senatorial Voting Behavior: The Argentine Case". Journal of Politics in Latin America 6 (2): 73-105.

Knight, Robert D. 2018. "Replication Data for: Strategic Coalitions and Agenda-Setting in Fragmented Congresses: How the PRI Sets the Legislative Agenda in Mexico". Brazilian Political Science Review 12 (2): e0001-33.

MacKenzie, Scott A. y Thad Kousser. 2014. "Legislative Careers". En The Oxford Handbook of Legislative Studies, editado por Shane Martin, Thomas Saalfeld y Kaare W. Strøm. New York: Oxford University Press, 286-308.

Krehbiel, Keith. 1991. Information and Legislative Organization. Ann Arbor: University of Michigan Press.

Ishiyama, John y Joy Langston. 2006. "The Changing Party of the Institutional Revolution: Electoral Competition and Decentralized Candidate Selection". Party Politics 12 (3): 395-413.

Langston, Joy. 2010. "Governors and 'Their' Deputies: New Legislative Principals in Mexico". Legislative Studies Quarterly 35 (2): 235-258.

Langston Hawks, Joy. 2013. "Delegación política en la Cámara de Diputados en México: de la hegemonía a la democracia". En Quién, cómo y qué se legisla en México, editado por Luisa Béjar Algazi. México: Universidad Nacional Autónoma de México-unAM, 43-81.

Loewenberg, Gerhard, Samuel C. Patterson y Malcolm E. Jewell. 1985. Handbook of Legislative Research. Cambridge: Harvard University Press.

Lundberg, Thomas Carl. 2007. Proportional Representation and the Constituency Role in Britain. Basingstoke: Palgrave Macmillan.

Magaloni, Beatriz. 2006. Voting for Autocracy: Hegemonic Party Survival and its Demise in Mexico. Cambridge: Cambridge University Press.

Martínez, María del Mar. 2006. “La carrera parlamentaria ¿La calidad importa?" En Políticos y politica en América Latina, editado por Manuel Alcántara Sáez. Madrid: Fundación Carolina y Siglo xxI, 91-125.

Masters, Nicholas A. 1961. "Committee Assignments in the House of Representatives". The American Political Science Review 55 (2): 345-357.

Mayhew, David R. 1974. Congress: The Electoral Connection. New Haven: Yale University Press. Morgenstern, Scott. 2006. "Limits on Exporting the U.S. Congress Model to Latin America". En Exporting Congress? The Influence of the U.S. Congress on the World Legislatures, editado por Timothy J. Power y Nicol C. Rae. Pittsburgh: University of Pittsburgh Press, 82-101.

Nacif, Benito. 2002. "Understanding Party Discipline in the Mexican Chamber of Deputies: the Centralized Party Model". En Legislative Politics in Latin America editado por Scott Morgenstern y Benito Nacif. Cambridge: Cambridge University Press, 254-284.

Piscopo, Jennifer. 2014. "Beyond Hearth and Home: Female Legislators, Feminist Policy Change and Substantive Representation in Mexico". Revista Uruguaya de Ciencia Política 23 (2): 87-110. 
Rodríguez, Victoria E. 2003. Women in Contemporary Mexican Politics. Austin: University of Texas Press.

Rosas, Guillermo. 2010. "Issues, Ideologies, and Partisan Divides. Imprints of Programmatic Structure on Latin American Legislatures". En Latin American Party Systems editado por Herbert Kitschelt, Kirk A. Hawkins, Juan Pablo Luna, Guillermo Rosas y Elizabeth J. Zechmeister. New York: Cambridge University Press, 70-95.

Rosas, Guillermo y Joy Langston. 2011. "Gubernatorial Effects on the Voting Behavior of National Legislators". The Journal of Politics 73 (2): 477-493.

Shugart, Matthew Soberg y John M. Carey. 1992. Presidents and Assemblies. Constitutional Design and Electoral Dynamics. Cambridge: Cambridge University Press.

Squire, Peverill. 1988. "Member Career Opportunities and the Internal Organization of Legislatures". The Journal of Politics 50 (3): 726-744.

Ugues Jr, Antonio, D. Xavier Medina Vidal y Shaun Bowler. 2012. "Experience Counts: Mixed Member Elections and Mexico's Chamber of Deputies". The Journal of Legislative Studies 18 (1): 98-112.

Ugues Jr, Antonio, D. Xavier Medina Vidal y Shaun Bowler. 2017. “Los Congresos Estatales y la Política Federal en México: State Legislatures and Federal Policymaking in Mexico". The Journal of Legislative Studies 23 (4:) 594-613.

Vázquez Ferrel, Carlos. 2017. La influencia legislativa de la oposición en las iniciativas presidenciales: el caso de los gobiernos en minoría en México, 1997-2012. México: Instituto Nacional de Administración Pública, A.C.

Recibido: 31 de mayo de 2018

Aceptado: 20 de mayo de 2019

Carlos Vázquez Ferrel. Doctor en Ciencia Política por la Universidad de Salamanca, España, e investigador en la Escuela de Gobierno del Tecnológico de Monterrey. Es autor del libro La influencia legislativa de la oposición en las iniciativas presidenciales: el caso de los gobiernos en minoría en México, 1997-2012. Correo electrónico: carlos.vazquez820308@gmail.com

Alejandro Díaz Domínguez. Doctor en Ciencia Política por la Universidad de Vanderbilt y profesor investigador en la Escuela de Gobierno del Tecnológico de Monterrey. Sus publicaciones más recientes se encuentran en Política y Gobierno, Perfiles Latinoamericanos y un capítulo coautorado en el libro Mexico's Evolving Democracy. Correo electrónico: alejandrod.dominguez@tec.mx 


\section{ANEXO}

Tabla 3. Estadística descriptiva

\begin{tabular}{|c|c|c|c|c|c|c|c|c|c|}
\hline & \multirow{2}{*}{ 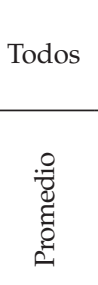 } & \multicolumn{2}{|c|}{$\begin{array}{l}\text { Presentación } \\
\text { de iniciativas }\end{array}$} & \multicolumn{2}{|c|}{$\begin{array}{l}\text { Proporción } \\
\text { iniciativas } \\
\text { aprobadas }\end{array}$} & \multicolumn{2}{|c|}{$\begin{array}{l}\text { Presidente de } \\
\text { comisión }\end{array}$} & \multicolumn{2}{|c|}{$\begin{array}{l}\text { Comisiones } \\
\text { relevantes }\end{array}$} \\
\hline & & 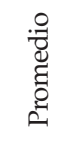 & 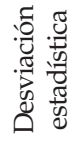 & 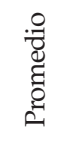 & 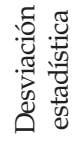 & 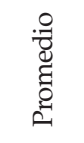 & 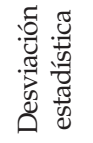 & 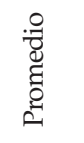 & 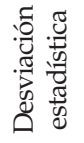 \\
\hline Mujer & 0,35 & 6,20 & 6,90 & 11,48 & 20,89 & 0,08 & 0,28 & 0,45 & 0,49 \\
\hline Hombre & 0,61 & 6,10 & 11,11 & 11,04 & 21,92 & 0,13 & 0,34 & 0,54 & 0,49 \\
\hline $\mathrm{RP}$ & 0,59 & 7,08 & 12,04 & 11,42 & 19,58 & 0,14 & 0,35 & 0,58 & 0,49 \\
\hline MR & 0,40 & 5,51 & 7,70 & 11,04 & 22,86 & 0,10 & 0,30 & 0,46 & 0,49 \\
\hline PAN & 0,24 & 5,08 & 5,50 & 12,03 & 20,70 & 0,11 & 0,31 & 0,52 & 0,50 \\
\hline PRI & 0,43 & 4,60 & 5,05 & 13,50 & 25,64 & 0,12 & 0,32 & 0,49 & 0,50 \\
\hline PRD & 0,15 & 6,54 & 6,56 & 6,80 & 14,52 & 0,11 & 0,33 & 0,51 & 0,50 \\
\hline PVEM & 0,60 & 6,71 & 5,80 & 13,90 & 21,39 & 0,12 & 0,33 & 0,57 & 0,49 \\
\hline MORENA & 0,02 & 3,40 & 2,60 & 4,02 & 17,19 & 0,08 & 0,27 & 0,37 & 0,49 \\
\hline Técnico normalista & 0,07 & 4,85 & 5,83 & 11,80 & 25,50 & 0,05 & 0,23 & 0,25 & 0,43 \\
\hline Licenciatura & 0,57 & 6,02 & 9,54 & 11,21 & 21,22 & 0,11 & 0,31 & 0,48 & 0,50 \\
\hline Posgrado & 0,24 & 7,23 & 12,19 & 11,85 & 21,99 & 0,16 & 0,37 & 0,65 & 0,47 \\
\hline Legislador local & 0,29 & 6,12 & 11,65 & 9,35 & 18,19 & 0,09 & 0,29 & 0,51 & 0,50 \\
\hline Legislador nacional & 0,60 & 6,19 & 6,07 & 11,26 & 23,31 & 0,15 & 0,36 & 0,52 & 0,50 \\
\hline $\begin{array}{l}\text { Legislador nacional } \\
\text { y local }\end{array}$ & 0,14 & 6,46 & 10,96 & 14,10 & 24,55 & 0,20 & 0,40 & 0,53 & 0,50 \\
\hline Líder partido local & 0,20 & 5,42 & 5,50 & 12,09 & 22,86 & 0,10 & 0,30 & 0,51 & 0,50 \\
\hline $\begin{array}{l}\text { Líder partido na- } \\
\text { cional }\end{array}$ & 0,07 & 7,68 & 17,07 & 10,12 & 19,62 & 0,16 & 0,37 & 0,57 & 0,49 \\
\hline $\begin{array}{l}\text { Líder partido político } \\
\text { local y nacional }\end{array}$ & 0,25 & 5,78 & 6,66 & 11,22 & 20,36 & 0,15 & 0,36 & 0,52 & 0,50 \\
\hline $\begin{array}{l}\text { Administrador pú- } \\
\text { blico local }\end{array}$ & 0,40 & 5,49 & 7,90 & 12,09 & 22,86 & 0,10 & 0,31 & 0,49 & 0,50 \\
\hline $\begin{array}{l}\text { Administrador pú- } \\
\text { blico nacional }\end{array}$ & 0,02 & 4,50 & 4,89 & 10,12 & 19,62 & 0,23 & 0,42 & 0,74 & 0,44 \\
\hline $\begin{array}{l}\text { Administrador públi- } \\
\text { co local y nacional }\end{array}$ & 0,01 & 5,27 & 5,55 & 11,22 & 20,36 & 0,47 & 0,51 & 0,47 & 0,51 \\
\hline Observaciones & 1.520 & & 1.250 & & 1.250 & & 1.520 & & 1.520 \\
\hline
\end{tabular}

Fuente: elaboración de los autores con información del banco de datos legislativos ITESM-FEMSA 


\section{Gráfico 5. Carrera partidista según género}

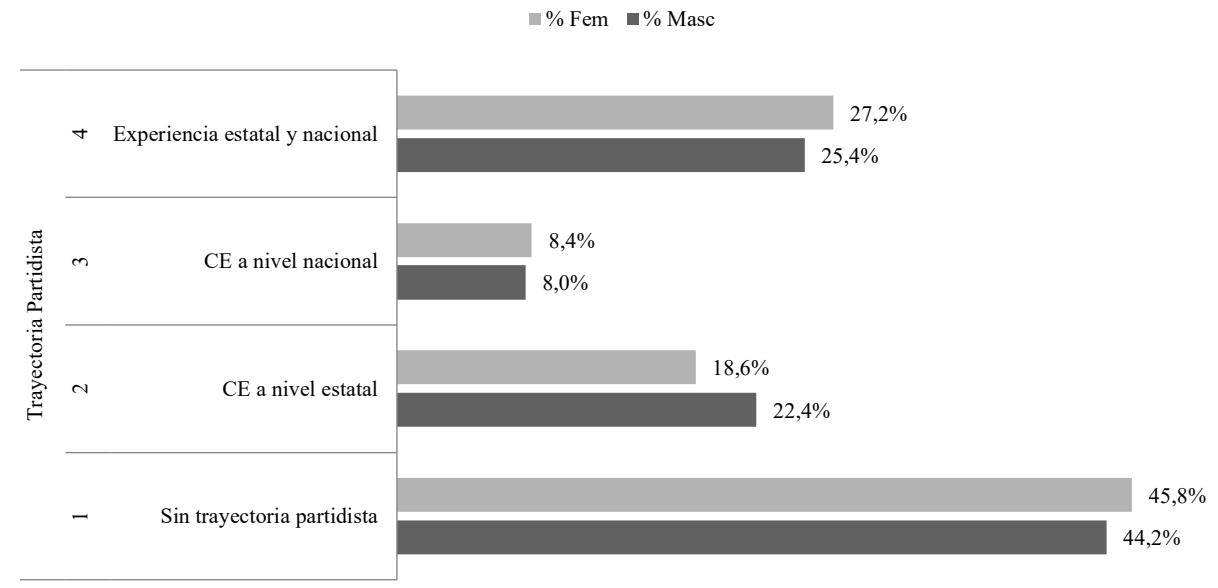

Fuente: elaboración de los autores con información del banco de datos legislativos ITESM-FEMSA

\section{Gráfico 6. Experiencia legislativa según género}

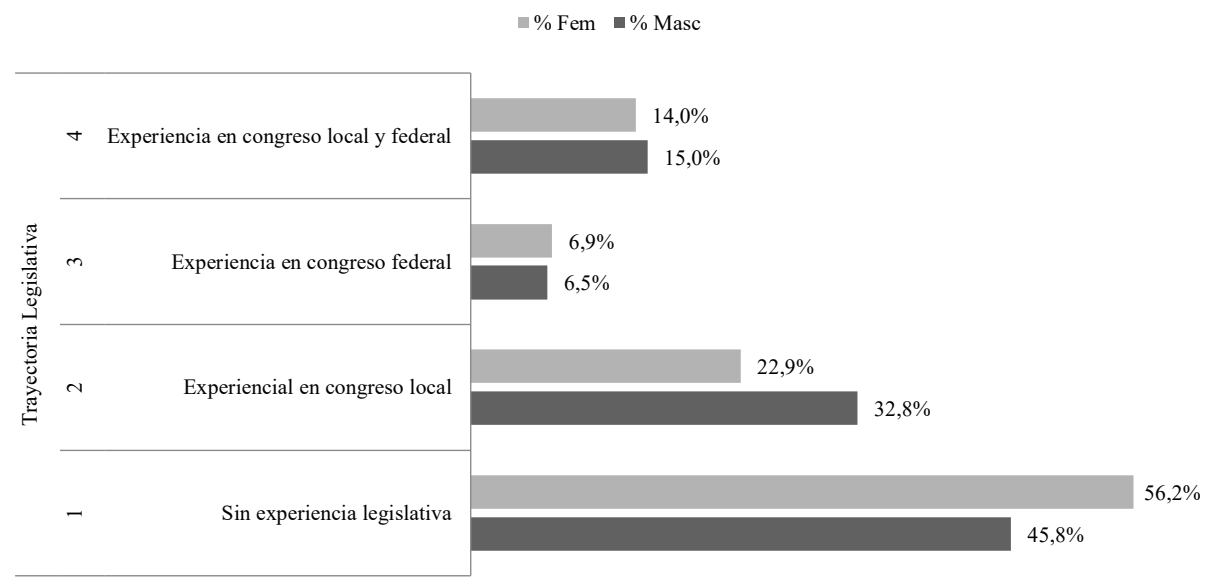

Fuente: elaboración de los autores con información del banco de datos legislativos ITESM-FEMSA 


\section{Gráfico 7. Grado de estudios según género}

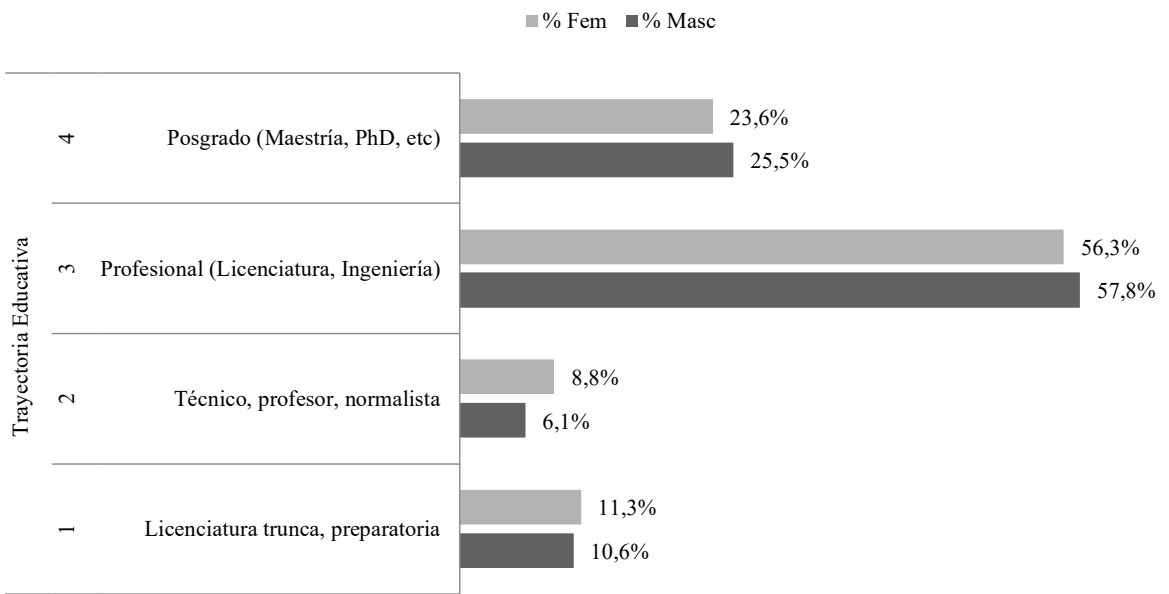

Fuente: elaboración de los autores con información del banco de datos legislativos ITESM-FEMSA

\section{Gráfico 8. Trayectoria en la administración pública según género}

$\%$ Fem $\quad \%$ Masc

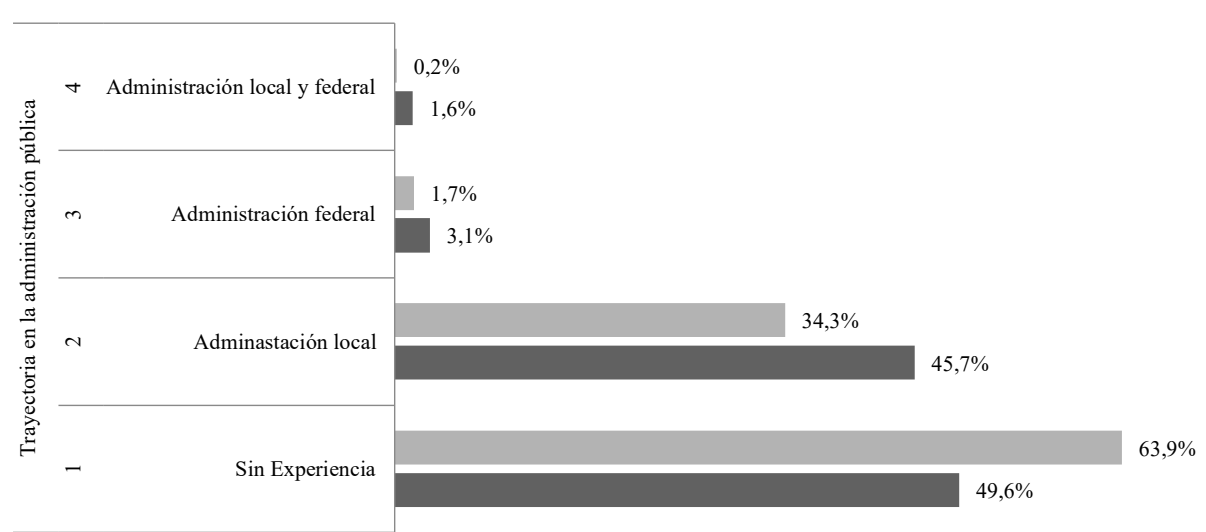

Fuente: elaboración de los autores con información del banco de datos legislativos ITESM-FEMSA 


\section{Gráfico 9. Carrera partidista según método de elección}

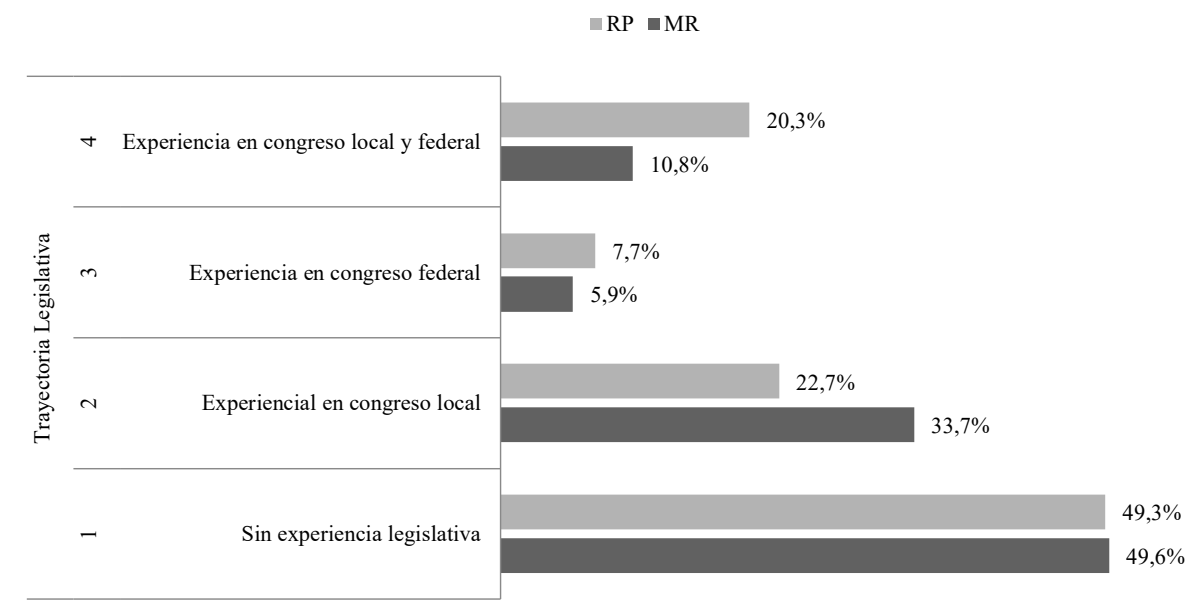

Fuente: elaboración de los autores con información del banco de datos legislativos ITESM-FEMSA

\section{Gráfico 10. Experiencia legislativa según método de elección}

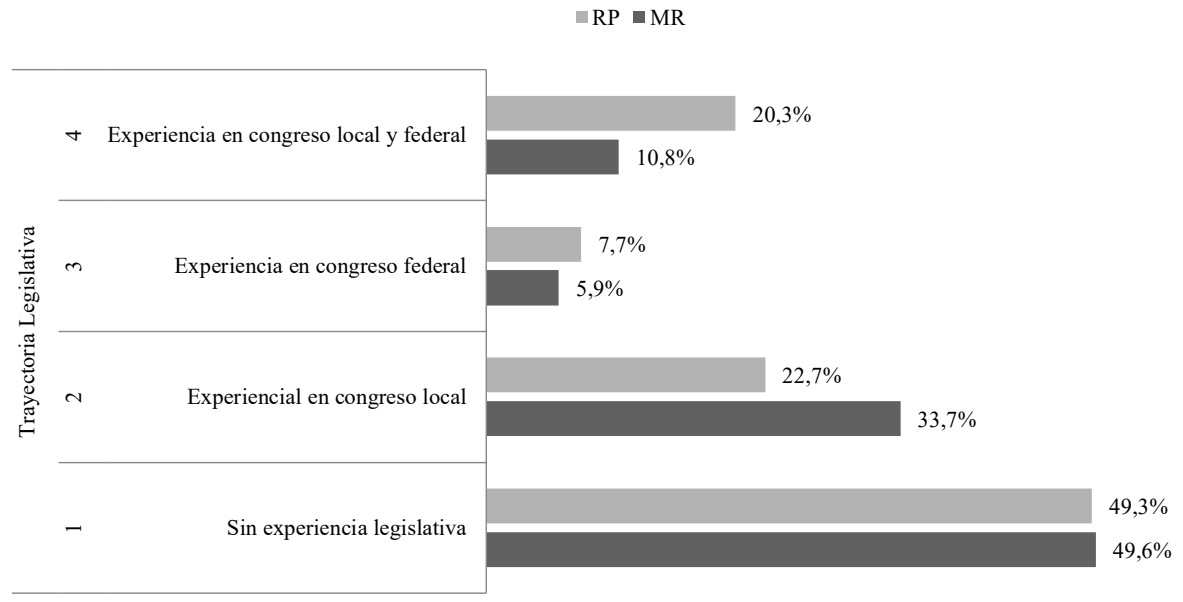

Fuente: elaboración de los autores con información del banco de datos legislativos ITESM-FEMSA 


\section{Gráfico 11. Grado de estudios según método de elección}

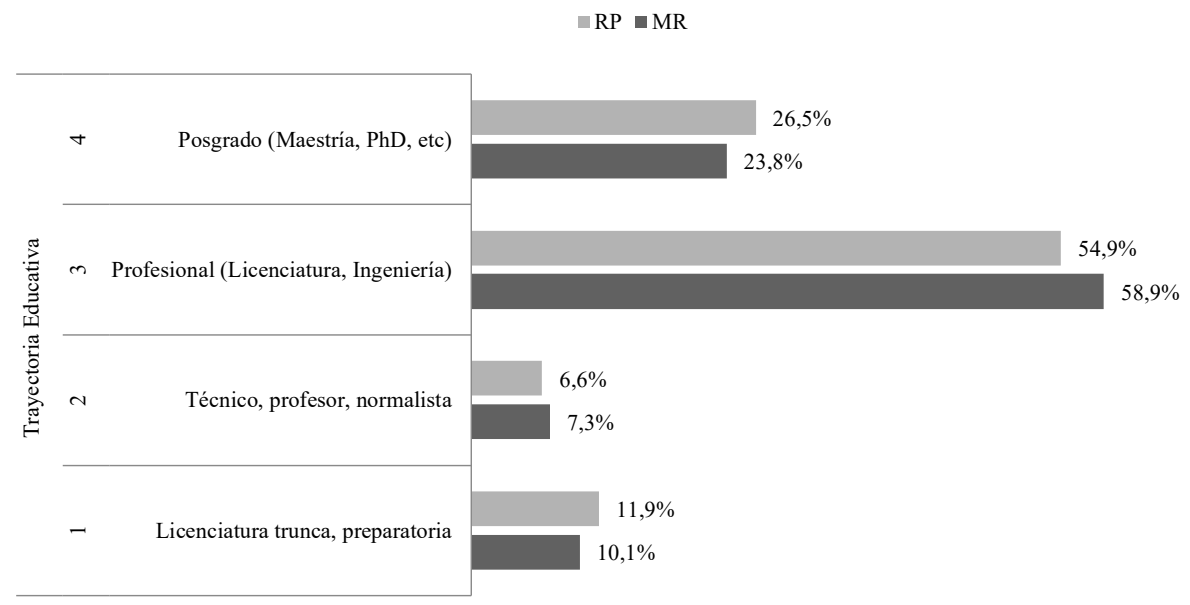

Fuente: elaboración de los autores con información del banco de datos legislativos ITESM-FEMSA

\section{Gráfico 12. Trayectoria en la administración pública según método de elección}

$\square \mathrm{RP} \square \mathrm{MR}$

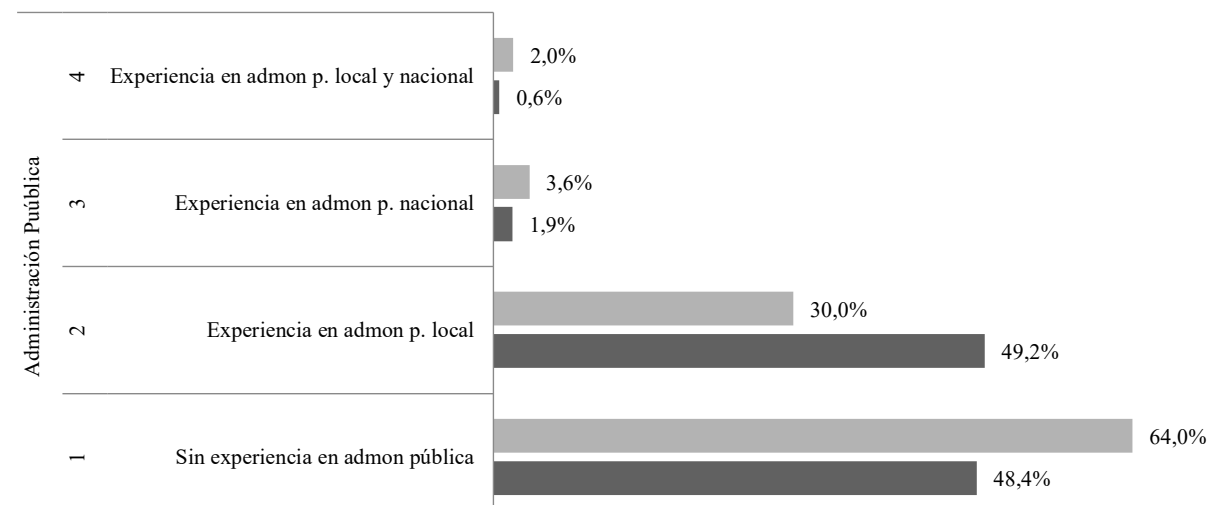

Fuente: elaboración de los autores con información del banco de datos legislativos ITESM-FEMSA 